\title{
Training and the small enterprises of Latin America
}

\section{Guillermo Labarca}

Human Resources Expert, ECLAC Division of Production, Productivity and Management.
The allocation of expenditure on training for the small enterprises of Latin America is a matter which requires clear guidelines. Increasing resources for this purpose is a necessary but not of itself sufficient strategy. The shortage of resources, their faulty allocation and the inefficiency in the use of those currently assigned to this class of enterprises are factors which make it necessary above all to take measures to ensure better use of the available resources, especially those of public origin. Likewise, it is necessary to find new sources of financing for training and upgrading the labour force, making use of suitable incentives. At the same time, it will be necessary to develop training techniques in keeping with the conditions of the countries of the region, to reform the existing institutions, and to establish new forms of relations among the actors concerned. 


\section{I}

\section{Introduction}

Training is an important issue in small enterprises, considering the extent to which the labour factor can help to raise productivity in the smaller industries of the region. Training plays an important role both in situations of technological change -which involve investments in machinery and equipment- and in processes of restructuring, reorganization and the application of new management techniques, which do not necessarily require substantial acquisitions of assets. Increasing the productivity of labour is an attractive possibility, especially for enterprises which have difficulty in gaining access to credit: that is to say, almost all the small enterprises of the region. Technological change, or the lack of it, has largely determined changes in productivity: indeed, it may be said that in the case of small enterprises this type of change has raised the productivity of labour more than that of capital. Innovations marked by increases in fixed capital have created fewer jobs per unit of investment than the previous practices, however.

If we take the approach of seeking to improve the productivity of small enterprises when analysing training and suggesting training policies, we are opting for the creation of more product per unit of capital. In other words, by preferring to improve the output per unit of investment rather than the employment per unit of investment, we are opting to create productive employment rather than non-productive employment but leaving aside the contribution that human resources training policies and initiatives can make to this process.

Small enterprises in general, especially in the industrial sector, tend to create more jobs per unit of capital than large enterprises, because of the link between technology and scale of production. The most efficient small enterprises occupy production and market niches where technologies making more intensive use of labour are currently more appropriate. Thus, for example, in a narrow market it is more efficient to produce made-to-measure clothing on a small scale than on a large scale, which means using labour-intensive technologies. The same is true in metalworking industries producing one-off parts or components, or spare parts not available from the regular spare parts suppliers. At the same time, however, the new technologies allow these enterprises to generate more product per unit of capital.

Lack of credit has probably been the greatest hindrance to the development of small enterprises in the region, for unlike Italy, Germany, Japan, the Netherlands, the Scandinavian countries, etc., in Latin America there are no regional banks or finance agencies to take care of the needs of the smaller industrial establishments, or even State policies designed to address these shortcomings in a systematic manner.

Training policies cannot correct shortcomings in the area of credit, but they can improve the profitability of the existing capital, increase the yield on new investments and create a favourable environment for endogenous innovation. They can do all this at a lower cost than investments in conventional capital, and with the advantage that the cost of investment in human capital can be shared out among the different actors involved: entrepreneurs, the State and the workers themselves. Finally, not only can the scale of the investments be smaller, but the total amounts of the investment can also be broken down into separate elements, so that investment plans for training can be tailored to the needs of an enterprise or group of enterprises.

Investments in human capital and the policies guiding them have a special nature: although, like any other investment, they are regulated by a market, this is influenced by exogenous factors such as:

i) the internal criteria of the training system (for example, prior performance and the certification that the system itself can provide);

ii) the fact that training is an ongoing process which is not completed once and for all within a predetermined period;

iii) the prestige accompanying training, which helps to create a demand for certain professions or trades rather than others;

iv) the fact that "wrong decisions" only become obvious in the long term, which makes it difficult to alter them promptly or correct them as a function of market trends, even though there may be drastic changes in the market. 
The most decisive consideration, however, is that connected with the imperfections in the training market, i.e., the characteristics of training from the point of view of the market value of the skills and know-how acquired by workers. If there were only two types of skills, as Becker assumes, or if all skills had only two aspects -i.e., either general or specificthere would be a better regulated market and probably more effective incentives. If it is assumed that general training, or the general part of specific training, is required by all enterprises and can be used in all jobs, while specialized training is specific to a single enterprise, this would solve the problem of the distribution of resources for training. If the knowhow and skills imparted by general training can be appropriated by all productive and social activities, the cost of the investments in such training should be paid by the trainees themselves, if wages are determined by the marginal productivity of labour, or else by society as a whole, while the cost of training which can only be appropriated by a single enterprise should be paid by the enterprise benefiting from such know-how.

The weakness in this argument is that there is almost no training which is completely specific. Almost all specific training is useful to a greater or smaller number of enterprises, but almost always to more than one, and this tends to discourage investment in training. The direct relation which exists between the degree of specificity of training and the investments made by enterprises in that field is well known, since the smaller the number of enterprises able to make use of certain skills, the greater is the marginal product of labour that they can appropriate. This relation between the possibility of appropriation of the marginal product and the employment possibilities of workers according to their know-how and skills determines the investments that enterprises are willing to make in human resources.

At the same time, the degree of specificity is closely related with the technologies used, and the these in turn are related with the minimum amounts of investment needed to apply them. This is why enterprises with low capital density (the great majority of small and medium-sized enterprises fall within this group) tend to use less specific technologies. This phenomenon is further strengthened by the comple- mentarity between capital and labour: when investments in human capital are insufficient, this reduces the productivity of physical capital, leading to a reduction in investments in more sophisticated machinery and technology and a failure to create new demands for human capital.

The close relation between training and formal education means that both in the formation of the supply and demand of skilled labour and in the identification of problems and the development of policies to overcome them there are considerations which affect the educational system. In fact, no really effective training policy can neglect this variable. Moreover, in the experience of the region and in international comparisons, especially with regard to small industrial enterprises, the general or special training of workers prior to their activities in the labour force is seen to be a conditioning factor, an element of facilitation, or the worst bottleneck in production performance and training for work.

The question of training in and for the small enterprises of the region also calls for some contextual clarifications and definitions and the consideration of certain data.

First of all, there is the actual concept of the small enterprise. This is usually decided by the number of employees and the income generated or the value added by the firm. This approach is probably less precise than that proposed by Ramos (1979), who suggests classifying enterprises in two main categories: those quoted on the stock exchange, which are the enterprises with access to financial capital, and those not quoted, which normally have chronic financing problems. The question of access to finance comes up repeatedly when analysing or formulating survival strategies and expansion policies for such firms, because it determines much of their economic behaviour and even affects their size.

Classifying firms by the number of employees and the volume of output has some practical use, since it makes it possible to establish some common specific features of a set of enterprises usually associated with the labour training processes.

Moreover, as we shall see below, when making a micro-analysis of labour training in a firm, the number of workers is a factor in defining the forms of training that can be most effectively applied and their cost/benefit ratio. 


\section{II}

\section{The cost of training for small enterprises}

A conservative estimate of the needs for specific training in industrial enterprises with fewer than 50 workers is that around $30 \%$ of the industrial labour force requires such training. ${ }^{1}$

The efficacy, cost and impact of labour training are associated with the prior educational level of the workers. In most cases, this is more decisive than the specific training itself for improving the workers' productivity. Lynch (1994), using data from studies on the member countries of the Organization for Economic Cooperation and Development (OECD), concludes that the training expenditure that enterprises have to make depends on the initial educational level of the labour force. In this respect, he notes that in the United States the performance of the labour force is below that of Germany and Japan (even in sectors where the expenditure by companies on training is not smaller), because the basic training of United States workers is deficient. This causes investment on training to have a low yield.

When considering the problem in all its complexity, it is necessary to take account not only of the present but also of the future needs of small enterprises, since human capital formation processes are slow and require more than just short-term measures. A full analysis of the situation must take into account the aspects conditioning the success of specific training. This means that human resources formation policies for small enterprises tend to blend with general training policies when analysing or embarking on the actions which form the basic foundation for training. At this level of policies and strategies it is very difficult to discriminate between and single out those which will specifically affect the sector of interest to us in this article.

The problem of basic skills is of vital importance and cannot be solved through targeting strategies. It is not possible to "target" an action affecting between $30 \%$ and $70 \%$ of the school-age population. Global policies are still needed in the region to ensure that all persons of appropriate age have access to certain

${ }^{1}$ Approximately 25,000 workers in Chile, between 80,000 and 90,000 in Argentina, 240,000 in Brazil and 120,000 in Mexico. benefits which they need in order to allow them to take their place in society, both for economic considerations and for reasons of equity. These policies are so general that it is not possible to formulate suitable strategies for a separate economic sector like that of small industrial enterprises without taking them into account.

This is important for the present study because an effective training policy must begin by solving some problems in respect of prior education. Many of the workers in the small enterprises of the region have a low level of education, which is in keeping with the fact that a substantial proportion of young Latin Americans do not receive secondary education. Only Argentina, Chile, Uruguay and some Englishspeaking Caribbean countries have net rates of secondary school enrollment ${ }^{2}$ which come close to or slightly exceed 50\% (UNESCO, 1998). Those who do not attend secondary school are divided up into the following categories: i) those engaged in formal sector employment, ii) those engaged in informal-sector activities, and iii) those who are unemployed. Most of those in the first of these categories are in fact apprentices. Those in the other two categories could greatly benefit from a well-designed system of apprenticeship.

A problem of a more general nature which affects small enterprises is that of persons (adults or schoolchildren) who are not yet in the labour market. Some efforts in the area of technico-professional school education, especially those involving alternating studies such as sandwich courses, aim to give such training mainly to persons of school age, while at the same time improving school education, in order to deal in this way with the shortcomings in terms of basic skills. There is a close relation between the characteristics of technico-professional school education and the needs of the smaller industrial enterprises. These forms of education are organized by the

\footnotetext{
2 The net rate of secondary school enrollment is the ratio of the number of secondary school students of the corresponding age (which varies in the different countries from a minimum of 12 to 14 years of age to a maximum of 17 to 18 ) to the total population in that age group.
} 
formal school education system for periods of at least three to four years, coinciding with the period of compulsory school attendance. They do not coincide with the time spans and strategies of the enterprises, however, which means that the latter tend to have little interest in participating in such training processes. This raises the difficult problem of turning schoolchildren into apprentices. Indeed, one may wonder if this is really possible on a large scale: perhaps a more realistic approach would be to start with apprentices and give them training in basic skills. This problem also arises in the integral training (basic skills and specific training) of adults and, in general, of all those who are not in a position to acquire the basic skills within the formal educational system.

The average educational level ${ }^{3}$ of a country is an approximate indicator of the educational level of the workers in small enterprises. For example, in the late 1980s the average number of school grades completed by the labour force as a whole was 3.3 in Brazil, 4.8 in Paraguay and Peru, 4.9 in Mexico, and 6 in the countries with the best average levels (Chile, Argentina, Uruguay and some former British possessions in the Caribbean). The latter may be considered as the minimum acceptable level for organizing effective training for work and incorporation into productive employment with outputs close to those of the best prevailing technological practices. Shortcomings in this field affect technological innovation and also labour performance. Typical difficulties include the inability of workers to convert centimetres into inches, to estimate curved surfaces and to calculate the pressure of liquids and gases, leading to inaccurate measurements and erroneous decisions that lead to waste.

\section{III}

\section{The cost of training and expenditure on education}

One way of gauging how far basic education facilitates more specific training is to estimate how much the cost of specific training is reduced when investments are made in improving school education (table 1).

The columns in section $\mathrm{A}$ of table 1 show the average cost of initial training of workers in sectors made up mainly of small enterprises in the region. The columns in section B show the saving for those same enterprises when the workers have approximately three years more of schooling. ${ }^{4}$ In countries where the coverage of basic education is close to $100 \%$, such as Argentina and Chile, the reduction in the training costs of enterprises achieved through extra investment in education tends to be close to zero. In countries with lower rates of primary educational coverage, however, the savings may be considerable, amounting in some cases to half the initial training costs. The cost of giving workers the necessary training in countries with the levels of schooling of Brazil, Mexico, Paraguay or Peru is high, but as we shall see

\footnotetext{
${ }^{3}$ The number of years of schooling completed by the population on average.

${ }^{4}$ Based on inter-firm comparisons of domestic and international firms.
}

below, if such training is provided at the school level the cost is less than if it is provided through compensatory programmes for adults. The main benefits for these countries are of a different nature: they provide suitable conditions for increasing productivity and achieving greater receptiveness for technological innovation.

The industrial sectors covered by table 1 are generally of low productivity in the region, but they currently employ a very high percentage of the total industrial labour force (between $40 \%$ and $70 \%$, depending on the country). Their low productivity is due above all to their low technological level: in order to achieve substantial increases in productivity major investments in machinery, equipment and organization are required. When such investments are made, however, persons with a low level of schooling are excluded because they do not have the necessary basic skills and, as we shall see below, because it is very costly to develop in adults the capacities needed to enable them to attain the cultural level demanded by the new technologies.

Enterprises, and especially the smaller ones, are almost exclusively interested in the provision of spe- 
TABLE 1

Latin America: Estimated cost of initial training, and saving on training expenditure through additional expenditure on school education a (1997 dollars)

\begin{tabular}{|c|c|c|c|c|c|c|}
\hline \multirow{2}{*}{ Sectors: } & \multicolumn{3}{|c|}{$\begin{array}{l}\text { Estimated cost of initial training needed } \\
\text { to secure a yield equal to the average } \\
\text { for the enterprise } \\
\text { A }\end{array}$} & \multicolumn{3}{|c|}{$\begin{array}{l}\text { Approximate percentage saving on training } \\
\text { expenditure achieved through additional }\end{array}$} \\
\hline & $\begin{array}{l}\text { Foodstuffs, } \\
\text { beverages } \\
\text { and tobacco }\end{array}$ & $\begin{array}{l}\text { Footwear, } \\
\text { wood and } \\
\text { furniture }\end{array}$ & $\begin{array}{l}\text { Pottery, } \\
\text { china and } \\
\text { porcelain }\end{array}$ & $\begin{array}{l}\text { Foodstuffs, } \\
\text { beverages } \\
\text { and tobacco }\end{array}$ & $\begin{array}{l}\text { Footwear, } \\
\text { wood and } \\
\text { furniture }\end{array}$ & $\begin{array}{l}\text { Pottery, } \\
\text { china and } \\
\text { porcelain }\end{array}$ \\
\hline Argentina & 200 & 600 & 300 & - & - & - \\
\hline Brazil & 188 & 450 & 225 & 48 & 37 & 41 \\
\hline Chile & 130 & 390 & 260 & - & - & - \\
\hline Colombia & 120 & 320 & 160 & 31 & 25 & 25 \\
\hline Costa Rica & 192 & 516 & 256 & 27 & 26 & 24 \\
\hline Guatemala & 103 & 246 & 123 & 49 & 40 & 87 \\
\hline Honduras & 136 & 318 & 159 & 50 & 42 & 39 \\
\hline Jamaica & 100 & 500 & 250 & 50 & 40 & 40 \\
\hline Panama & 392 & 980 & 490 & 52 & 37 & 53 \\
\hline Peru & 110 & 290 & 160 & 32 & 21 & 80 \\
\hline Dominican Republic & 152 & 363 & 182 & 47 & 27 & 42 \\
\hline
\end{tabular}

Source: ECLAC Industrial Dynamics Analysis Programme (PADI), and surveys.

${ }^{\text {a }}$ Prepared on the basis of minimum wages, information from surveys of enterprises, and projections.

${ }^{b}$ The average yield was estimated on the basis of information obtained from the enterprises: it includes the costs in respect of induction and training of new workers and the difference in their output during the period they need to reach the average for the enterprise.

${ }^{c}$ The additional expenditure is equivalent to three years' coverage per individual. It is based on public expenditure per student on primary education in 1990. Average productivity of $50 \%$ of the enterprise average is assumed during the period. Only wage costs are included. Costs on material and equipment, loss of raw materials, supervisors' salaries, etc. are not included.

cialized training: they have no incentive to invest in the formation of basic skills. The biggest hindrance to investments of this type is the rotation of the skilled labour force, and important factors in such rotation are the level of training of a worker and his work experience, which increase the market value of the individual. There is a systematic drain of workers from small enterprises to medium-sized and large firms in the region, and this is the biggest hindrance to the promotion of training activities. The big firms reduce the amount of training that they have to provide because, as they are in a position to pay better wages, they hire workers who have already acquired working experience in smaller firms. For their part, the small firms have no incentive to upgrade the skills of their labour force more extensively, because they do not always obtain any benefits from such investment.

In order for enterprises to become interested in training in basic skills it would be necessary to establish incentives which must necessarily be higher than the cost to them of the rotation of the labour force and the risks involved in the investment. Such a pol- icy is hard to implement. A more efficient approach would appear to be the proposal made by Ramos (1994), who, inspired by Becker, suggests a private loan market for investments in human capital. According to Ramos, the lack of loans explains why there is faulty resource allocation in the economy, which adversely affects efficiency and equity. He suggests that a system of loans should be established which uses pension rights as a guarantee. This proposal takes account of the fact that the worker is the first person to be benefited by training and it is he who obtains the know-how and skills, thus justifying the notion that he should absorb the costs of the process. This strategy would also make it possible to establish more efficient quality controls: since it is the worker himself who pays for his training, he will be more demanding in terms of the yield on his investment, thus eliminating the less profitable offers from the training market.

Comparisons with Southeast Asia and with certain sectors of some European countries indicate that the improvements in organization and processes gen- 
TABLE 2

Latin America: Additional cost of increasing schooling by three years, and hypothetical effects on the employment status ${ }^{a}$ of the population aged 15 or more (1997 dollars)

\begin{tabular}{|c|c|c|c|c|}
\hline Countries & $\begin{array}{l}\text { Additional cost } \\
\text { of increasing } \\
\text { first-level } \\
\text { schooling by } \\
\text { three } \\
\text { years } \\
\text { (US\$ '000) }\end{array}$ & $\begin{array}{l}\% \text { wage increase } \\
\text { due to improvement } \\
\text { in employment status } \\
\text { thanks to increased } \\
\text { expenditure on } \\
\text { first-level schooling } \\
\text { (simulation) }\end{array}$ & $\begin{array}{l}\text { Additional cost } \\
\text { of increasing } \\
\text { second-level } \\
\text { schooling by } \\
\text { three } \\
\text { years } \\
\text { (US\$ '000) }\end{array}$ & $\begin{array}{c}\% \text { wage increase } \\
\text { due to improvement } \\
\text { in employment status } \\
\text { thanks to increased } \\
\text { expenditure on } \\
\text { second-level schooling } \\
\text { (simulation) }\end{array}$ \\
\hline Brazil & 105542 & 18.3 & 670928 & 2.3 \\
\hline Bolivia & 2162 & 6.9 & 173377 & 5.8 \\
\hline Chile & 16731 & 7.1 & 56027 & 23.0 \\
\hline Colombia & 58013 & 9.8 & 219871 & - \\
\hline Costa Rica & 6435 & 14.5 & 56037 & 25.2 \\
\hline Guatemala & 14935 & 24.3 & 66750 & 26.0 \\
\hline Mexico & 49878 & 19.7 & 1439123 & 20.4 \\
\hline Panama & 12600 & 17.5 & 40242 & 31.9 \\
\hline Paraguay & 2070 & 12.2 & 34907 & 34.7 \\
\hline Uruguay & 13740 & 13.8 & 21325 & 18.3 \\
\hline Venezuela & 22134 & 17.3 & 58163 & 21.2 \\
\hline
\end{tabular}

Source: ECLAC, special tabulations of household surveys of the respective countries; UNESCO, 1998.

${ }^{a}$ Employment in more productive activities.

${ }^{\mathrm{b}}$ From first to sixth grade.

${ }^{\mathrm{c}}$ From sixth to tenth grade.

erated within the production units can become a very important source of higher productivity. The factors which act most negatively in inhibiting the generation and application of endogenous innovations in the enterprises of the region are educational shortcomings and the forms of management used. The style of development prevailing in Southeast Asia and Japan stimulates such innovations because, among other reasons, in those areas of the world the educational levels of the labour force are functional to forms of management which encourage the creativeness of each worker.

Increased expenditure on school education also has effects on the distribution of costs. By reducing the cost of later training and increasing productivity through the improvement and expansion of primary education, the government is assuming costs which would otherwise have to be paid by entrepreneurs and/or workers. Furthermore, the expansion of educational services produces other benefits, such as greater flexibility and adaptability of the labour force, better preparation for coping with technological innovation or the reconversion of production, and greater capacity to contribute to the development of new technologies. In-house innovation is not a normal practice in the region, because of a number of organizational and cultural factors, and it would seem unlikely that this practice can be developed when there are shortcomings in the basic skills.

In all the countries of the region, the saving on initial training thanks to better school education is particularly visible in industries such as footwear, wood and wood products (excluding wood pulp), furniture and non-metallic fittings. These industries employ techniques which are of an almost artisanal nature and are labour-intensive, and the skilled labour they use is trained mainly on the job; they therefore depend to a large extent on the levels of initial training that workers have when they join the firm. The saving thanks to better school education in the foodstuffs and beverages sector is smaller in absolute terms, but it is high as a proportion of the cost of initial training. The techniques used by the enterprises in this category tend to involve less skilled labour.

Even though a good general training is profitable, and entrepreneurs know this, they are reluctant to invest in this area because it only gives returns in the medium or long term. Moreover, the final benefit for them may be zero, because training in basic skills 
stimulates labour rotation. The conclusion with regard to policy formulation is fairly obvious: it is necessary to create incentives which operate in the short term for workers to take part in training, and to apply educational policies which facilitate the access to (formal and informal) education by those under 17, rather than to continue to concentrate on incentives to entrepreneurs (through tax deductions, for example).

Assuming that the relation between primary and secondary education and occupational status is main- tained, table 2 shows the effect of investments designed to improve the educational level of the segments of the population with the lowest levels of schooling. The figures show that their occupational status would be improved if there was an improvement in primary and secondary education, with an increase in the coverage of the latter producing more significant effects than an increase in primary education. The effects would be reflected both in the type of employment and in wage levels.

\section{IV}

\section{Compensatory training}

The alternative of employing persons with a low level of schooling and making up for their educational shortcomings through training involves very high investments - just as high as or higher than the training itself- and it is less efficient than the option of employing persons with at least ten years' schooling.

The available information gives grounds for concluding that the processes of the technical substitution of capital for labour are accompanied by greater demand for workers with an educational base equivalent to secondary education. When they do not have this educational base, it is necessary to consider programmes for bringing their education up to the necessary level. In the best of cases, the compensatory training to make up for the main shortcomings caused by lack of secondary schooling at the age of 18 or more would take some 20 months, with approximately 25 hours of study per week. ${ }^{5}$ After this period, the persons in question would be in a position to start initial training proper, which, in the leading industries of the region, lasts from 2 to 4 months before full incorporation into the production line.

The estimated cost of programmes like these in various countries of the region is shown in table 3 . This cost is the opportunity cost for the workers, if they pay for the compensatory programme directly; for the enterprises using more advanced technologies which find workers with schooling or experience in the labour market; or for the State, if it decides to

\footnotetext{
${ }^{5}$ Examples of such programmes are those provided by the Fun-
} dación DUOC in Chile.
TABLE 3

Latin America: Cost of compensatory programmes, compared with cost of secondary education ${ }^{\mathrm{a}}$ (1997 dollars per person)

\begin{tabular}{lcc}
\hline Country & $\begin{array}{c}\text { Compensatory } \\
\text { programme } \\
\text { (20 months) }\end{array}$ & $\begin{array}{c}\text { Four years of } \\
\text { secondary } \\
\text { education }\end{array}$ \\
\hline Argentina & 2285 & 412 \\
Brazil & 1220 & 669 \\
Chile & 1714 & 677 \\
Colombia & 1372 & 270 \\
Ecuador & 1437 & 317 \\
Guatemala & 641 & 185 \\
Honduras & 916 & 317 \\
Jamaica & 1118 & 795 \\
Dominican Republic & 1029 & 191 \\
\hline
\end{tabular}

Source: UNESCO, 1998, and ECLAC data.

${ }^{\mathrm{a}}$ The present cost of education was estimated at a $10 \%$ annual discount rate over the 1990 expenditure. The present opportunity cost is based on the 1994 minimum wages, with an $0.8 \%$ monthly discount rate.

assume these costs. This does not depend on the educational model applied, but on the role assigned to the government with regard to human resources training. Although compensatory programmes may be designed to bring persons with shortcomings in terms of secondary school education up to the desired level, they are treated as training programmes, so that they will be determined by the policy instruments governing the latter and the emphasis they place on the supply or demand side.

When their emphasis is on supply, it will be the State which has to defray a major part of the costs, as well as establishing mechanisms of evaluation, con- 
trol and certification for such programmes which will bring them closer to school education. When the emphasis is on demand and there is a close link between the training and the formation of basic skills, the costs will tend to be assumed by the workers, and/or the enterprises, and/or the State (through subsidies for demand by individuals or by enterprises). The biggest difficulties in implementing these programmes, however, do not lie in their cost but in factors of an institutional nature such as certification, the formulation of curricula, coordination with the demands of production activities, etc.

The compensatory training costs shown in table 3 have been estimated on the basis of the average cost of the existing programmes in the region, after eliminating extreme cases. All of them also assume an opportunity cost for the workers equivalent to the minimum wage: a very conservative hypothesis in the case of persons working in enterprises using more advanced technology, or even many own-account workers. A level of productivity of $50 \%$ is assumed during the period of compensatory training. These values are compared with the present cost of four years of conventional secondary education, according to the educational expenditure of each country, that is to say, on the hypothesis that the current levels of quality are maintained. ${ }^{6}$

The present cost and externalities of the two alternatives would naturally make it advisable to opt for school education, whose cost is between 0.5 and 8 times less than that of compensatory programmes after the age of 18 . The adoption of this alternative as the only and exclusive form of training, however, would mean overlooking the fact that there is a very considerable contingent of workers in the region who are over that age yet lack the basic skills demanded by modern industry and could therefore benefit from compensatory programmes.

The sectors shown in table 1 above are of a low level of technological development, and in the region they operate with production functions and labour densities that would presumably require an educational level equivalent to at least six years' primary schooling.

\footnotetext{
${ }^{6}$ The compensatory programmes and the four years of secondary education are not strictly equivalent: they are therefore not substitutable goods. The comparison is useful, however, because it provides background information for policy formulation.
}

With regard to persons who are already working, it may be wondered whether training at this stage can really make up for their shortcomings in terms of general education, to what extent, and under what conditions. The experience of several countries of the region shows that such training cannot take the place of basic education, which has special features and develops skills that workers are assumed to possess already when their training is begun.

Training schemes which include elements of general education may be attractive to enterprises whose conventional capital component is very high, but such schemes would not have the same effect on the composition of the total investments of enterprises whose production functions are more labourintensive and whose fixed capital is smaller, even though their labour force might be the same size. Trying to apply them in firms which have not replaced labour with capital and are not in a position to do so would force them to devote a larger proportion of their investment to human capital formation.

This raises two questions. First, whether capital/labour mixes which involve relatively greater use of labour need, or can benefit from, such intensive training processes. Second, whether an investment with an unusually large component relating to human resources formation is cost-efficient. These questions affect decisions on the advisability of investing directly in training, more or less independently of the investment in physical capital.

Although it is not possible to give categorical answers, there are some indications which can guide these kinds of decisions. With regard to the first question, the benefit that industries with high capital density achieve through the organization of general training schemes is that these schemes provide training in general basic skills while at the same time developing specific skills for use in the sector to which the industry belongs. This is necessary in order to bring workers up to a level of physical output similar to that of comparable industries in the industrialized countries, by improving both their general and specific training: that is to say, bringing them up to a level comparable with that of the workers in many German or Japanese firms who have completed their initial training.

In the industrialized countries, it is not only the leading-edge firms which have workers of this educational level, nor are these firms the only ones that give their workers intensive training in specific tech- 
niques. Much of the productivity of the firms in those countries, be they old or new, large or small, is due to the level of training of their workers. In Japan, for example, the length of training does not necessarily depend on the production function of the firms. In Germany, it is generally acknowledged that the level of education and skills in the production units is very high, regardless of their size or the sector in which they operate, as is the productivity of labour.

It is not only productivity which is associated with training in the industrialized countries, however, but also the capacity of the industrial sector to make technological innovations. The possibility of constantly incorporating new technologies into production is subject, among other things, to the availability of staff with the skills described above.

Transferring the experience of those countries to the region, it may be concluded that training of this nature can also benefit enterprises whose production functions are less capital-intensive. The question is to determine what conditions are needed for the application of these schemes in firms less committed to the accumulation of human capital.

First of all, there is the question of cost. In addition to the initial expenditure per worker on training there are further costs in respect of materials, instructors and training premises, as well as the opportunity cost involved in bringing the workers up to average productivity levels after their training period is completed. It is hard for enterprises making intensive use of labour to decide to engage in such expenditure, and even if they were willing and able to do so it is doubtful whether they would be able to achieve a level of productivity that would make them competitive enough to make up for the investment.

Furthermore, such investment is not very attractive to entrepreneurs because it usually means greater labour force rotation. The mobility of workers is often a result of the training they have received, which leads them to seek better-paid or own-account jobs in the same sector.

One of the chronic problems for industries in the region is the mobility of their employees. Giving workers greater skills will not help to solve this prob- lem unless complementary measures of a social nature are adopted, as some enterprises have done (day nurseries, production bonuses, bonuses for long service in the enterprise, skills incentives, etc.). ${ }^{7}$ These measures involve additional costs and undoubtedly call for substantial changes in management practices.

Finally, raising the basic educational level of workers may be dysfunctional to the enterprise in as much as it creates expectations about the type of employment they can hope to obtain. Fleury and Humphrey (1993) report, on the basis of a sample of enterprises in São Paulo and Rio Grande do Sul, that in Brazil a worker who improves his educational level and receives a certificate to prove it expects to "rise" to an administrative post. According to these authors, in order to have production workers with high levels of schooling it would be necessary to increase the total coverage of the educational system; if this is not done and only the education of some workers is improved, the latter will look for work away from the field of production.

This observation is confirmed by the relation which exists between the educational level of production workers and the average schooling of the population. The tendency described above is more frequent in countries like Brazil, which have a low level of schooling, than in Chile or Argentina, where the school enrollment rate of the population between 7 and 14 years of age is close to $90 \%$, and it is even rarer in the industrialized countries, which have $100 \%$ educational coverage.

These differences are parameters that must be taken into account when designing policies. In training, as in other areas of economic activity, there are economies of scale which affect the relative efficiency of the various options. The technical and institutional instruments of a policy designed to raise the skills of over a hundred thousand workers are different from those of a policy designed for twenty thousand. In the first case, distance education techniques will be more efficient, while in the second it may be preferable to establish local training centres, which would not be effective, however, for serving a large contingent of workers.

\footnotetext{
${ }^{7}$ Among the enterprises which have done this are Fantuzzi in Chile and Hofab in Jamaica.
} 


\section{V}

\section{Appropriateness of training}

Another matter is the arguments questioning the appropriateness of the training currently provided for small and medium-sized enterprises. In all the studies made, the entrepreneurs have expressed unfavourable opinions on the training available outside the firm itself. The most usual criticism is that the courses do not take account of technical progress and the tools, machinery and practical exercises used in them are far removed from the real work of the students. For their part, the workers interviewed often report that rather than helping them develop skills and capacities that will be useful to

\section{VI}

\section{Apprenticeship}

In almost all the countries of the region, efforts are being made to implement forms of training which replace both in-school technical training and job training with systems of apprenticeship or sandwich courses, inspired by the dual system used in Germany, which has also been successfully applied in Switzerland and Austria. This system seeks to establish a permanent relationship between the enterprises and training, not only in the management of the training activities, as some vocational training institutes have been doing at least since the 1950s, but also and above all in the teaching practice itself. The most important workshops and training areas are the industries themselves.

Although the relation between the enterprise and the educational institution lies at the heart of the concept of sandwich courses, the problem is broader than that of the organization of a dual educational system. Other sectors of vocational training, such as in-school technical and professional education and training for production activities, also need to establish ongoing collaborative relations with the production sector. None of them has achieved this yet in the region, although all analyses and policy proposals link the them in their daily work, the training courses provide them with certificates and diplomas which may improve their market value. These views are most frequently expressed in sectors such as mechanical engineering, gasfitting, carpentry and various activities connected with the production of metal goods. Many school and out-of-school activities for training human resources in the region have been organized by the educational or training systems, that is to say, it has been the educational sector which has taken the initiative, giving rise to the concept of the "student apprentice". shortcomings in training systems with the their lack of connection with the production units. The various efforts made so far have had varying results, but none of them has provided solutions suitable for largescale application or for use in dual education. It would appear that such linkages as do exist have occurred in exceptional conditions. The challenge that this represents is of enormous importance today for any form of training, especially systems of sandwich courses.

There are currently no effective incentives for enterprises to take part in the planning, execution and evaluation of training programmes. How can the enterprises of the region be expected to take an interest in training if no Latin American country has the tradition of training or social consensus-building that exists in Germany? This question brings us to a problem of incentives. It is a challenge to find the right incentives, but one of them is connected with the financing of this form of training, since the costs that it involves for the enterprises are always a deterrent to taking part in the system.

It would be premature at present to express a final judgment on the efforts which are under way. 
They have been successful in their current experimental stage, but they are receiving heavy international support, especially from Germany.

The experiments made along the lines of sandwich courses are particularly interesting for small enterprises, because they are associated with certain forms of organization of production and certain types of production functions. Dual training links up better with artisanal-type enterprises, where there are strong relations between the master and the apprentice, and medium-sized or large enterprises that have a flexible form of organization.

The forms referred to here -sandwich courses, vocational training institutes, technical educationare those that can be developed or modified by a training market and by State policies, whose coverage is currently limited, since only some enterprises and an even smaller proportion of small enterprises and their workers benefit from them. This does not mean that the enterprises and workers outside this system do not provide or receive training. It is necessary to see how they do this and evaluate the effi- ciency of their actions, however. There are large enterprises which train their staff even though they run the risk of losing skilled workers and try to make the workers help to pay for the training costs by deductions from their wages. There is no systematic information available on the forms of training used in small enterprises outside the training market. There is scattered evidence that they do provide training, but the available information is not sufficient to formulate more general views.

The details of the on-the-job training provided by these enterprises (duration, cost, number of apprentices, implicit forms of certification, appropriateness, recurrence, etc.) vary according to the branch they operate in, their size, and their technological level. The supervisors play a central role in these processes, especially when dealing with new workers.

A detailed knowledge of what takes place in the small enterprises of the region, and the dissemination of such knowledge, could be useful for preparing more general strategies. There can be no doubt that detailed research needs to be carried out on this matter.

\section{VII}

\section{Considerations with regard to policy formulation}

\section{Merely increasing expenditure is not enough}

The main reason why this strategy would not be enough is that the increase in training expenditure that the countries of the region would be in a position to finance would not be sufficient to satisfy the real demand of small enterprises, even if it were allocated entirely to enterprises with less than 50 workers.

If public and private training resources are not sufficient to serve the whole population and all the enterprises that need these services, then a way of sharing them out must be sought. The market would not appear to be the most efficient mechanism for this purpose, for the reasons set forth below.

The demand for any type of training is highly elastic and tends to increase more rapidly than the supply of training, thus immediately affecting the quality of the services provided. Furthermore, because of the characteristics of training viewed as a good -since it is at once a consumer product and an investment- the demand for it is not regulated by the market mechanisms. Training as a good is so complex that we could really speak of a number of different goods, with demand elasticities associated with the different levels and products offered. Even within each of these products, there are different goods that affect the elasticity of demand. Vocational training institutes, for example, offer a main product (training proper), plus a series of sub-products (know-how, prestige, access to other levels of education, access to certain types of employment, etc.) which are often seen as just as desirable as the training itself, if not more so.

In contrast, the supply of training is much more inelastic, and attempts to regulate supply and demand through the market mechanisms have not had the expected results.

Public expenditure on training does not seem to be efficient, for various reasons. Among those of a 
general nature are the fact that training systems rarely guarantee access to the employment market, that they are relatively costly, and that they often fail to take account of the heterogeneity of industry and are in many cases not in keeping with the needs of the most modern sectors. Among the factors that particularly affect small enterprises are: i) cost; ii) the study requirements, which mean overwork or the absence of trainees from productive work, which is hard for small enterprises to accept, and iii) the fact that the recruitment criteria of such enterprises do not attach much importance to the qualifications provided by vocational training bodies. However, no-one opposes an increase in such expenditure. In all countries, there are declarations and promises of such increases, which are not questioned because there is general agreement on the virtues of vocational training and it is recognized that there are market failures in this field. This latter fact hinders greater private intervention and places greater demands on the public sector.

The inappropriateness of public training programmes is a phenomenon that is also to be observed in the OECD countries (The Economist, 1996). A number of studies reveal that hardly any of the training programmes financed by governments comply with the objectives of improving productivity and creating more and better employment.

Priorities need to be set for public expenditure on training. They could be set by the institutions responsible for the distribution of the corresponding resources, by the users of those services, or by a combination of the two. If it is decided to give users the leading role in this respect, it would be desirable at the same time to provide incentives and suitable conditions for expenditure by individuals on their training, both with respect to the generation of resources and the management of the State contribution. Both individual expenditure and better management of State resources could be more effective than the present systems of expenditure and management.

It would therefore be desirable to seek other definitions which would help to guide private resources, when there are other alternative uses for them, and which determine where public investment should be made. Mixed solutions such as the tax exemptions established in a number of countries of the region (which make expenditure by enterprises on training tax-deductible, up to a total equivalent to $1 \%$ or $2 \%$ of their payroll) have not been very satisfactory, especially in the case of small enterprises. Entrepreneurs who are reluctant to make use of these arrangements usually complain that the benefits provided are not sufficient to pay for the courses offered by training agencies, so that they have to make a supplementary contribution which they consider to be expensive, and that the training programmes do not satisfy the current needs of workers and enterprises: that is to say, they are not appropriate.

At all events, if what is considered important is productivity, then this should be made the main criterion. From this point of view, there are three types of small enterprises which warrant priority attention:

i) Enterprises which have shown themselves to be more productive (than small enterprises in less productive branches or sectors, or medium-sized or large enterprises in the same branches or sectors). ${ }^{8}$

ii) Enterprises in danger of losing productivity. These are enterprises which were productive in the past but are in danger of losing this quality because they are beginning to lag behind in the technological innovation process. For these enterprises, training should form part of a general strategy designed to keep them ahead in terms of technology, complemented with investment plans that involve technological innovation. This group of enterprises have already shown that they can be productive, and they have accumulated technical know-how and management capacity which represent a store of social capital worth preserving.

iii) Enterprises located in potentially productive sectors. Small enterprises which have horizontal and vertical linkages are particularly worthy of attention, especially when they form part of production clusters, since natural resource-based production clusters appear to be an interesting development option.

\section{Appropriate training technologies}

The different scales and forms of problems in the different countries mean that the strategies needed must be different too. The scale of training needs in

\footnotetext{
${ }^{8}$ In order to identify these enterprises, Ramos (1979) suggests a methodology based on inter-firm comparisons for constructing an index of the economic efficiency of the main factors (capital and labour). He concludes that the yield on capital provides the best approximation for estimating the sectoral yield. In operational terms, this means the value added, less wages, divided by the total assets. This manner of estimating productivity has the advantage of maximizing the yield of a factor which is very scarce among small enterprises, namely, capital.
} 
Brazil or Mexico, for example, is very different from the needs in Chile or Bolivia. In the first two countries, small industrial enterprises are relatively more developed, the degree of geographical dispersion is greater, and the population is much larger, so that they need solutions which are different from those appropriate to smaller countries. However, the strategies followed in, for example, Argentina, Brazil, Colombia and Venezuela have all been centered on vocational training institutes, although the small industry sectors of those countries are all of different sizes. The main feature of these institutes is that they offer training organized on the basis of trades and job descriptions. This method may be effective when two conditions are fulfilled: that the training agency maintains constant contact with the beneficiary firms with regard to the selection of the workers to be trained and the formulation of the study programmes, and that there is an ongoing follow-up of the evolution of the persons trained. In the region, this is only possible when the beneficiary firms are few in number and easily accessible. In addition, however, the training agencies must also display flexibility in adapting their supply to changing conditions, and this is not so in the case of such agencies as the National Industrial Training Service (Brazil), the National Industrial Training and Labour Service (Peru), the National Council for Technical Education (Argentina), etc.

Not every enterprise is fitted to participate in every form of training. Dual training, for example, can be introduced in enterprises at the two technological extremes, that is to say, enterprises which use non-capital-intensive technologies and a skilled labour force, or enterprises which are highly capitalintensive but have a flexible form of organization. For this reason, sandwich courses give better results in artisanal-type enterprises, where there is a strong master-apprentice relationship, and in medium-sized and large enterprises with a wide range of functions and a system of working in teams which calls for adaptability. Enterprises of medium and high capitalintensiveness, using technologies involving great specialization of tasks and rather inflexible forms of organization, are not suitable for dual training. Examples of such enterprises are those in the nonautomated textile and clothing industries, some food industries, and engineering firms with continuous production lines: that is to say, the types of industries set up and the technologies adopted during the import substitution period. Much of the industrial sector (es- pecially in the case of medium-sized and large firms) still uses such technologies.

The production system in the region is very heterogeneous. Medium-sized and small enterprises with an artisanal production structure, medium-sized and large enterprises which are technologically backward and have a rigid form of organization, and flexibly organized modern enterprises of all sizes coexist with each other. Some enterprises are also internally heterogeneous, however, with technologically advanced departments operating side by side with very backward ones. Generally speaking, in medium-sized and large enterprises technological modernization begins in the area of management (especially financial management), subsequently extends to administration, and finally reaches the field of production. The reasons for this sequence are complex and will not be analysed here, but it is worth bearing them in mind when planning vocational training activities. It is by no means rare to find enterprises that are capable of training excellent management personnel yet are unable to give proper training to production workers.

At all events, collaboration between the production and educational sectors means that the enterprises themselves, or entrepreneurs' associations, should take initiatives in these matters or participate from the beginning in the formulation and implementation of training policies through coordination bodies. The ministries of the economy or labour should also be directly involved in policy formulation.

One of the most important elements of the new training technologies is that they are organized on industrial lines for the large-scale production of training material for direct use by the trainees.

In view of the financial situation of the region, the tendencies in terms of restructuring and the experience of other sectors, it seems both possible and necessary to consider radical solutions for the problem of financing training: just as radical as those now being applied in some health or pension systems. There are at least three financial and accounting items which are of decisive importance in this respect: the salaries of the instructors, the wages of the trainees, and the infrastructural costs. It might be desirable to develop strategies which begin within the production units, based on the idea of "student apprentices". In other words, the training process would be considered as beginning on the job, and training would be seen as a response to the demands of production activities. 


\section{The incorporation of graduates of training courses into employment}

In general, the problem of incorporating training graduates into employment arises in respect of those graduating from training systems with characteristics similar to those of school education: that is to say, systems structured in the light of their own supply rather than outside demand. The problem is not so serious in the case of apprenticeship-based (i.e., production-based) training for young people and young adults who are already employed. In this case, what is needed is to find incentives to persuade these persons to go through this period of apprenticeship.

The innovations in human resources formation and the training of young people made in technical schools, in dual training systems, and in a large part of the vocational training institutes will not affect workers already engaged in industrial production activities, who will be left on the sidelines of any improvements in these areas. It is highly probable that over $80 \%$ of those currently working will still be working ten years from now, that at least $60 \%$ of them will still be working in another 20 years, and that over half of the current labour force will continue working for a further 30 years. In addition to this contingent, there are all those young people who are currently entering the labour force, and those who will do so in the years to come, without having received the benefit of the possible progress in vocational training inside and outside schools. Any reform in the system of pre-employment vocational training will only show tangible effects in at least five years' time. The question of on-the-job training is therefore of crucial importance if it is really desired to improve levels of productivity.

\section{Dispersion or concentration}

The cost and efficacy of vocational training are linked with locational variables. Economies of scale can be achieved through proper geographical distribution of training institutes.

\section{Sectoral and structural heterogeneity of small and medium-sized enterprises}

This is another factor that must be taken into account when designing training strategies for small and medium-sized enterprises, although this phenomenon is not restricted to them. The heterogeneity of economies is nothing new: it has been recognized and analysed at least since the beginning of the industrialization process. The economies of the region have always been described as displaying "duality", "unequal development", etc. When considering the question of human resources in relation with the technological differentiation between sectors and within each sector and subsector of the economy it is necessary to take into account the increasingly divergent trends in technological development and the fact that there are many enterprises that use heterodox technological mixes. Both of these factors have helped to accentuate technological diversity.

Thus, as well as being related with a number of factors that were already well-known, diversification is now also seen to be linked with the fragmentation of production processes. This type of diversification is to be seen in printing and furniture manufacture, among many other possible examples: in plants that are on the leading edge of technology, flexible processes associated with digital control and computation are carried on side by side with processes organized on the basis of highly traditional trades and structures of work. In both cases, this is because technologies impose certain types of behaviour and because of the type of inter-firm relations that have been growing up. Differences are also often due to factors which are more widely known and studied, such as distance behind the technological frontier, size of the firm, etc., which are observed in all the societies studied. Although the differences in question are not completely new, they are now being observed to an unprecedented extent. These aspects of technological evolution are often not taken into account when designing policies or strategies regarding the supply of qualified personnel, as may be seen from the analyses and justifications of educational and human resources formation policies.

Small and medium-sized enterprises are the weakest points in the industrial fabric of the region. They have displayed a chronic inability to close the technological gap separating them not only from the most advanced international practices but also from those of big firms oriented towards the domestic market. The two most important means of satisfying their human resources requirements are technical schools and, above all, on-the-job training. All the governments of the region have applied policies to improve the supply of skilled personnel of all levels, but the 
results have not always been very satisfactory. Nor have policies of subsidies or direct attention to the demand for such personnel by small and mediumsized enterprises been satisfactory either. There are a number of obstacles which make it difficult on the one hand to define that demand, and on the other, to implement such policies. Among these obstacles are the size of the enterprises, the feebleness of their efforts to form associations to make up to some extent for the shortcomings connected with their size, and the imperfections in the information available to them. For these same reasons, these enterprises do not benefit either from the progress made by the big firms in the adaptation of technology and the training of human resources. Small and medium-sized enterprises that manage to occupy positions in the first line of the production chain of a technologically advanced industry do manage to improve their levels of technology and human resources training, but they are only a minor fraction of the overall universe of firms. All this points to the need to develop effective information and training strategies for that universe.

(Original: Spanish)

\section{Bibliography}

Dirven, M. (1995): Propuesta para inclusión en el paper sobre innovación tecnológica en el agro, Santiago, Chile, Economic Commission for Latin America and the Caribbean (ECLAC), mimeo.

Fleury, A. and J. Humphrey (1993): Human resources and the diffusion and adaptation of new quality methods in Brazilian manufacturing, Research Report, No. 24, Brighton, U. K., University of Sussex, Institute of Development Studies.

Gitahy, L. and F. Rabello (1991): Educação e desenvolvimento tecnológico: o caso da indústria de autopeças, Textos para discussão, No. 11, São Paulo, Brazil, State University at Campinas.

Lynch, L. (1994): Training and the Private Sector: International Comparisons, Chicago, Illinois, University of Chicago Press.

Moock, P. and R. Bellew (1988): Vocational and Technical Education in Peru, Washington, D. C., World Bank.
Ramos, J. (1979): Tecnología, capacitación y empleo, in PREALC (Regional Employment Programme for Latin America and the Caribbean), México: la pequeña industria en una estrategia de empleo productivo, "Investigaciones sobre empleo" series, No. 17, Santiago, Chile, International Labour Organisation (ILO).

- (1994): Síntesis del planteamiento de la CEPAL sobre equidad y transformación productiva, "Desarrollo Productivo" series, No. 17, LC/G.1841, Santiago, Chile, ECLAC, December.

Schiefelbein, E. and J. Farrel (1982): Eight Years of their Lives: Through Schooling to Labor Market in Chile, Ottawa, Canada, International Development Research Centre (IDRC).

The Economist (1996): London, 6 April.

UNESCO (United Nations Educational, Scientific and Cultural Organization) (1998): Statistical Yearbook 1998, Paris. 